\title{
Castellia tuberculosa (Moris) Bor (Gramineae) nuevo taxón para Extremadura (España)
}

Josefa López ${ }^{1}$, Enrique Rico² \& Juan Antonio Devesa ${ }^{3}$

${ }^{1}$ Área de Botánica, Facultad de Ciencias, Universidad de Extremadura, avenida de Elvas s. n., 06006 Badajoz (España)

${ }^{2}$ Departamento de Botánica y Fisiología Vegetal, Campus Miguel de Unamuno, 37007 Salamanca (España)

${ }^{3}$ Departamento de Botánica, Ecología y Fisiología Vegetal, Facultad de Ciencias, Universidad de Córdoba, Campus de Rabanales, edificio José Celestino Mutis, ctra. de Madrid km 396 A, 14014 Córdoba (España)

\section{Correspondencia}

J. López

e-mail: josefalopez@unex.es

Recibido: 12 julio 2021

Aceptado: 25 agosto 2021

Publicado on-line: $x x x x x 2021$

Editado por: Marta Recio Criado

\begin{abstract}
Resumen
Se da a conocer la presencia de Castellia tuberculosa en Extremadura, donde ha sido localizada en la provincia de Cáceres.
\end{abstract}

Palabras clave: Castellia tuberculosa, corología, Gramineae, Cáceres, Extremadura, Península Ibérica.

\begin{abstract}
Castellia tuberculosa (Moris) Bor (Gramineae) new taxon for Extremadura (Spain)

First record for Extremadura (Spain) of Castellia tuberculosa is located in Cáceres province.
\end{abstract}

Key words: Castellia tuberculosa, Chorology, Gramineae, Cáceres,

Extremadura, Iberian Peninsula.
Castellia tuberculosa (Moris) Bor in Ind. Forest. 74: 90 (1948) [Catapodium tuberculosum Moris in Atti Riunione sci. Ital.: 481 (1841), basión.]

CÁCERES. Belvís de Monroy: riberos del Tajo, margen derecha aguas abajo de la presa de Valdecañas, [X275992Y4406398], Datum WGS84, pastos de terófitos bajo ejemplares de Retama sphaerocarpa, en bordes de camino y taludes, sobre cuarcitas y pizarras, $260 \mathrm{~m}, 01-\mathrm{V}-2021$, E. Rico \& C. Urones, ER 8612 (SALA 170439, UNEX 37865).

Castellia tuberculosa (Moris) Bor es un terófito termófilo, circunmediterráneo, irano-turánico y macaronésico que, de manera más precisa, se distribuye por el $\mathrm{S}$ de Europa (Península Ibérica, Grecia y las islas de Ibiza, Cerdeña y Sicilia), $\mathrm{N}$ de África (Marruecos, Argelia, Túnez y Libia), S y SW de Asia (Palestina, Arabia, Irán, Paquistán, Afganistán e India) y Macaronesia (Canarias) (López \& Devesa, 2020). En la Península lbérica se conocía del SE y S de España [A Ab Al Ca Co H J Ma Mu Se] y el Baixo Alentejo portugués y en las Baleares para la isla de Ibiza (López \& Devesa, 2020).

La especie, que habita en pedregales, bordes de camino, taludes, arenales marítimos, baldíos y lugares removidos (López \& Devesa, 2020), ha sido recientemente localizada en la provincia de Cáceres viviendo en pastos cercanos a la presa del embalse de Valdecañas, en zonas muy soleadas de orientación sur y sobre sustrato ácido, aunque en las proximidades se encuentran afloramientos de calizas cámbricas. Este hallazgo constituye una novedad corológica para Extremadura y amplía el área de distribución al centro de la península de este taxón poco frecuente en la flora peninsular. Las localidades más próximas de las que es conocido son las del Baixo Alentejo, cerca del límite con las provincia de Badajoz y Huelva (Pereira \& Porto, 2021), la cordobesa mencionada por Domínguez et al. (1985) y una de Sevilla en el término municipal de El Pedroso (COFC 25283), todas ellas distantes algo más de 200 $\mathrm{km}$ en línea recta de la nueva localidad cacereña. No obstante, es posible que esta especie se encuentre en otras zonas de Extremadura, pero que haya pasado desapercibida al confundirse a simple vista y en el campo con otras gramíneas de aspecto similar, sobre todo con especies de Micropyrum (Gaudin) Link, ya que el carácter diagnóstico de Castellia, el lema cubierto de pequeños tubérculos, solo se observa al ojo desnudo cuando las espiguillas están maduras, y con cierta dificultad; la posibilidad de haber pasado inadvertida entre otras gramíneas ya fue considerada por Domínguez et al. (1985) al citarla por primera vez para el sur de la Península Ibérica. La especie, al igual que pasa desapercibida, tampoco es raro que se identifique de forma errónea, como sucedió con la primera cita para la provincia de Sevilla (Morales et al. 1998), la cual se basó en un material mal determinado (Constantina, Las Baltrotas; COFC 25333), por ello, y a buen seguro, resultaría interesante seguir investigando la distribución de este taxón para la flora ibérica. 


\section{Agradecimientos}

Este estudio ha sido subvencionado por el Ministerio de Ciencia e Innovación a través de los proyectos CGL2017-85204-C3-2-P y CGL2017-85204-C3-3-P, cofinanciados por el Fondo Europeo de Desarrollo Regional.

\section{Bibliografía}

Domínguez, E., Arenas, M. \& Ruiz de Clavijo, E. (1985). Castellia tuberculosa (Moris) Bor, nueva para el sur de la Península Ibérica. Anales del
Jardín Botánico de Madrid, 41, 461-462.

López, J. \& Devesa, J.A. (2020). Castellia Tineo. In J.A. Devesa et al. (eds.), Flora iberica 19(I) (pp. 376 -379). Madrid: C.S.I.C.

Morales, M., Delgado, J.M., Torrecilla, A., Tamajón, R. \& Muñoz, J.M. (1998). Novedades corológicas para la comarca de Sierra Norte en la provincia de Sevilla. Lagascalia, 20, 316 -331.

Pereira, A.J. \& Porto, M. (2021). Castellia tuberculosa (Moris) Bor -mapa de distribuição. Flora on: Flora de Portugal Interactiva. Sociedade Portuguesa de Botânica.

http://www.flora-on.pt [consultado el 7-07-2021]. 